\title{
EDUCAÇÃO AMBIENTAL NA AGRICULTURA FAMILIAR: UMA ANÁLISE NO MUNICÍPIO DE TUPÃ-SP
}

\author{
Daniel Sá Freire Lamarca ${ }^{1}$ \\ Silvia Cristina Vieira ${ }^{2}$
}

Angélica Gois Morales ${ }^{3}$

\begin{abstract}
RESUMO
Considerando o enfoque da agricultura familiar como importante produtora e fornecedora de alimentos in natura e de matérias-primas para agroindústrias, e também a grande importância que a educação ambiental possui no meio rural, este trabalho tem como objetivo identificar os conhecimentos e práticas de educação ambiental na Agricultura Familiar na região de Tupã-SP. O método utilizado nesta pesquisa foi exploratório e descritivo, com coleta de dados por meio de formulário aplicados para produtores familiares da região. Os resultados obtidos demonstraram que quanto às práticas executadas, é em grande maioria, realizada por fazer parte da legislação e, em relação às percepções dos agricultores sobre o assunto, foi percebido que a grande maioria dos produtores acredita que é necessário conservar o meio ambiente para que haja uma melhor qualidade de vida. Contudo, faz-se necessário uma melhor implantação da educação ambiental no meio rural para que seja possível obter avanços com um desenvolvimento sustentável.
\end{abstract}

Palavras chave: Agricultura Familiar, Educação Ambiental, Sustentabilidade.

\section{ENVIRONMENTAL EDUCATION IN FAMILY FARMING: AN ANALYSIS IN THE CITY OF TUPÃ-SP}

\begin{abstract}
Considering the focus of family farming as a major producer and supplier of fresh food and raw materials for agro-industries, and also the great importance that environmental education has in rural areas, this study aims to identify the knowledge and environmental education practices in Family Agriculture in Tupa-SP region. The method used in this research was exploratory and descriptive, with data collection through a form applied to family farmers in the region. The results showed that as the practices performed, most in is held to be part of the legislation and, with respect to perceptions of farmers on the subject, it was realized that the vast majority of producers believe that it is necessary to conserve the environment for there is a better quality of life. However, better implementation of

\footnotetext{
1 Discente em Administração, Universidade Estadual Paulista - UNESP - Campus de Tupã. lamarca@tupa.unesp.br. Bolsista de Iniciação Científica FAPESP. Membro do projeto de extensão universitária Competências Digitais para Agricultura Familiar (CoDAF).

${ }^{2}$ Mestranda em Agronegócio, especialista em gestão de agronegócios. Universidade Estadual Paulista - UNESP - Campus de Tupã. tinavieiragomes@hotmail.com.br. Membro do grupo de Pesquisa em Gestão e Educação Ambiental (PGEA) e do projeto de extensão universitária Competências Digitais para Agricultura Familiar (CoDAF).

${ }^{3}$ Professora Assistente Doutora do curso de Administração. Universidade Estadual Paulista - UNESP - Campus de Tupã. angelica@tupa.unesp.br. Líder do grupo de Pesquisa em Gestão e Educação Ambiental (PGEA).
} 
environmental education it is necessary in rural areas so that you can make progress with sustainable development.

Key-words: Family Farming, Environmental Education, Sustainability.

\title{
EDUCACIÓN AMBIENTAL EN LA AGRICULTURA FAMILIAR: UN ANÁLISIS EN LA CIUDAD DE TUPA-SP
}

\begin{abstract}
RESUMÉN
Teniendo en cuenta el enfoque de la agricultura familiar como un importante productor y proveedor de alimentos frescos y materias primas para la agroindustria, y también la gran importancia que tiene la educación ambiental en las zonas rurales, este estudio tiene como objetivo identificar los conocimientos y prácticas de educación ambiental en la Agricultura Familiar en la región Tupa-SP. EI método utilizado en este estudio fue exploratorio y descriptivo, con la recolección de datos a través de una forma aplicada a la agricultura familiar en la región. Los resultados mostraron que a medida que llevan a cabo las prácticas, más lo es considerada parte de la legislación y, con respecto a las percepciones de los agricultores sobre el tema, se dio cuenta de que la gran mayoría de los productores creen que es necesario para conservar el medio ambiente para hay una mejor calidad de vida. Sin embargo, una mejor aplicación de la educación ambiental es necesario en las zonas rurales para que pueda avanzar en el desarrollo sostenible.
\end{abstract}

Palabras clave: Agricultura Familiar, Educación Ambiental, Sostenibilidad.

\section{INTRODUÇÃO}

A educação ambiental está presente em várias instituições nos últimos anos, pois muitos setores da economia estão levando em consideração a sustentabilidade, para que haja um planejamento de produção contínua sem degradação do meio ambiente. Desse modo, o estudo e aplicação de teorias sobre gestão ambiental, na qual engloba análises sobre educação ambiental, se torna cada vez mais importante dentro das organizações.

Assim sendo, dependendo do ramo de atividade em que a empresa está inserida, pode haver uma variação do grau da sua relação com as práticas de gestão ambiental. Nesse contexto, as instituições que estão ligadas ao agronegócio possui uma relação direta com essas práticas, já que grande parte dos recursos utilizados no processo produtivo provém da natureza e do meio ambiente.

A partir disso, a agricultura familiar por fazer parte do complexo do agronegócio, também deve ter suas responsabilidades com relação às práticas ligadas aos processos de gestão e educação ambiental e, assim deve ocorrer um planejamento dos produtores familiares, quanto aos sistemas de produção que utilizam em sua cultura, podendo essa cultura ser do tipo agrícola ou pecuária. Uma dessas relações é o desenvolvimento rural sustentável, que é um conceito fundamental em projetos de gestão ambiental no meio rural. Neste cenário, a 
educação ambiental possui o intuito de compreender o meio ambiente com uma visão sistêmica, incluindo o agricultor como mais um elemento do ecossistema, refletindo a qualidade de vida no campo a partir da relação agricultor e natureza, a fim de reduzir os impactos ambientais negativos.

Conforme citam Neumann e Loch (2002), o Brasil possui características ecológicas espaciais muito distintas, sendo que determinada solução pode apresentar resultados completamente diversos, principalmente quando variam essas características, o que torna impossível propor soluções ambientais padronizadas voltadas ao meio rural.

Há uma grande complexidade de ecossistemas e sistemas produtivos que variam de grandes latifúndios a pequenas áreas de produção familiar, e não há uma legislação ambiental específica para cada realidade, o que dificulta o fomento ao desenvolvimento rural sustentável e práticas ambientais customizadas para cada necessidade.

A atuação governamental poderia demandar uma gestão ambiental com enfoque mais educativo e menos punitiva, onde o papel do educador ambiental rural seria elemento de articulação do fomento à conscientização dos agricultores para suas necessidades sociais. Além disso, poderia promover a educação ambiental de maneira que ocorra uma eficiente utilização dos recursos naturais, em que visa à transformação das ações antrópicas no meio rural e uma melhor qualidade na permanência do individuo no campo.

O fato de a gestão ambiental estar baseada essencialmente nos mecanismos fiscalizatórios e coercivos, tem reflexos danosos para o desenvolvimento global da sociedade, em particular no meio rural. Agrava, ainda mais, a precária situação de sobrevivência de grande parcela dos agricultores familiares, pois onera o processo produtivo agrícola e também não propicia os elementos básicos, na qual permitam ao público envolvido o cumprimento de suas obrigações (NEUMANN; LOCH 2002).

É de senso comum que o meio rural é associado à natureza, considerado o cenário no qual o ser humano está em contato direto com o meio ambiente, no entanto muitas vezes, com ineficientes ações de conservação e preservação ambiental. Um agravante para esta pluralidade de valores no campo é o uso de insumos químicos sintéticos, utilizado para melhorar a produtividade dos alimentos. 
Outro ponto a ser analisado é o uso de recursos naturais, muitas vezes de maneira pouco eficiente e racional por parte dos produtores rurais que não detêm informações suficientes a respeito de educação ambiental.

Como normatização da Política Nacional de Educação Ambiental no Brasil conta-se com a Lei no 9.795 de 27 de abril de 1999, que possui como definição em seu artigo primeiro define:

Educação Ambiental como os processos por meio dos quais o indivíduo e a coletividade constroem valores sociais, conhecimentos, habilidade e atitudes voltadas à conservação do meio ambiente, para promover a qualidade de vida e a sustentabilidade (BRASIL, 1999).

A educação ambiental não é somente a aquisição de conhecimento, mas também a mudança de comportamentos e atitudes, possuir habilidades para realizar ações e busca de soluções para os problemas ambientais (VICTORINO, 2000).

O campo do saber da educação ambiental possui um viés de atuação interdisciplinar, sendo que no ambiente rural encontra-se num processo de construção mais lento que no urbano. As ações são isoladas e a população possui menor acesso a informações ambientais que a população urbana. Para tanto, devese atuar de maneira participativa, incluindo os atores locais desde a elaboração do projeto até a devolutiva com a discussão dos resultados finais e possíveis ajustes futuros.

Segundo Sauvê (2005), a educação ambiental não é uma "forma" de educação simplesmente, não é uma "ferramenta" para resolução de problemas ou de gestão do meio ambiente. Trata-se de uma dimensão essencial referente a educação fundamental que trata interações que encontra-se na base do desenvolvimento pessoal e social: a relação do ambiente que vivemos de maneira compartilhada. Neste sentido, o foco da educação ambiental encontra-se concentrada na relação ser humano e sociedade, construindo novos saberes para proporcionar um ambiente sustentável contribuindo com a qualidade de vida, tanto nas cidades como no campo.

Portanto, a educação ambiental deve priorizar a construção do conhecimento, respeitando os saberes do produtor rural e, nesse contexto, 0 processo dialógico deve apresentar alternativas viáveis ao agricultor e a comunicação assumir um papel importante na mediação de construção e 
reconstrução do conhecimento ambiental por meio da Educação Ambiental. Dessa forma,

\begin{abstract}
A questão ambiental não pode se resumir a expressões como "é proibido", "é vedado", "não é permitido", "sanções penais", "auto de prisão"; mas deve postular a construção de conhecimentos, através de situações específicas da realidade, como forma de produzir intervenções humanas adequadas às condições singulares. Neste sentido, cresce a tomada de consciência de que muitos dos problemas dos instrumentos de gestão ambiental empregados decorrem de um conhecimento insuficiente das condições e modalidades de produção existentes, bem como da consequente inadequação das alternativas propostas aos agricultores (NEUMANN; $\mathrm{LOCH} 2002)$.
\end{abstract}

Quando bem realizada, as ações de educação ambiental alcançam mudanças de comportamento pessoal, de atitudes e de valores de cidadania que podem ser fortes consequências sociais. Isso acontece porque comportamento "ambientalmente correto" é aprendido na prática do cotidiano, por meio de gestos de solidariedade, hábito de higiene pessoal e dos diversos ambientes, entre outras expressões positivas (MEC, 2001).

Tais práticas de educação ambiental levam a um desenvolvimento sustentável pautado no tripé da sustentabilidade no meio rural. Conforme Leff (2007, p.246), "os desafios do desenvolvimento sustentável implicam a necessidade de formar capacidades para orientar um desenvolvimento fundado em bases ecológicas de equidade social, diversidade cultural e democracia participativa”.

Kageyama (2008), afirma que o desenvolvimento rural, por sua vez, não deverá ser identificado somente por meio do desenvolvimento econômico, mas visualizado por meio de um olhar abrangente, permeando um processo que envolve múltiplas dimensões: a econômica; a sociocultural; a politico-institucional e principalmente a ambiental.

Neste sentido, e com uma visão sistêmica de análise do ambiente rural, o papel da interdisciplinaridade torna-se fundamental e reforça as competências do educador ambiental, além da importância das pesquisas científicas para corroborarem com as práticas do desenvolvimento rural sustentável.

Complementa Morales (2012), que o enfoque interdisciplinar é tomado como um possível meio do educador ambiental chegar à reformulação do pensamento, com a incorporação de fundamentos teóricos adequados. Sendo assim, imprescindível para a reflexão e o encaminhamento de soluções às dificuldades relacionadas ao ensino e as pesquisas realizadas nos diversos campos do saber. 
Para atingir diretamente produtores da agricultura familiar ${ }^{4}$, também é importante que o educador ambiental adote linguagem apropriada à comunicação rural. Segundo Bordenave (1983), para entender a comunicação no meio rural, torna-se necessário identificar as formas de agir e de pensar do homem rural, que por muitas vezes acabam gerando códigos e meios de comunicação próprios e particulares, construindo modelos específicos de comunicação.

Sabe-se que o segmento familiar da agricultura nacional é responsável por grande parte da produção agropecuária, apresentando assim relações estreitas com o segmento industrial e de serviços, o que resulta em uma importante participação no PIB do agronegócio brasileiro (GUILHOTO et al., 2007). Dessa maneira, possui grande importância na produção agrícola brasileira, sendo que no ano Censo Agropecuário de 2006, $84 \%$ do total do número de propriedades rurais eram de atividade familiar e, além disso, é responsável por aproximadamente $74 \%$ dos empregos gerados no campo (CODAF, 2015).

A importância deste segmento para o país é comprovada, entretanto, é pouco valorizado quando se trata de políticas públicas e a atuação do governo no setor, se comparado com outros segmentos, como por exemplo, o da agropecuária empresarial (AZEVEDO e PESSÔA, 2014).

Para que os números na agricultura familiar continuem tendo uma boa representatividade no setor do agronegócio nacional, há algumas políticas do governo federal que incentivam um aumento de produção e produtividade dos agricultores familiares em todo o país. Dentre esses programas, estão: Programa Nacional de Fortalecimento à Agricultura Familiar (PRONAF), Programa Nacional de Alimentação Escolar (PNAE), Programa de Aquisição de Alimentos (PAA), Programa de Garantia da Atividade Agropecuária da Agricultura Familiar (PROAGRO), Programa de Garantia de Preços para a Agricultura Familiar (PGPAF) e Programa Nacional de Crédito Fundiário (PNCF) (MDA, 2015).

É importante destacar que programas como o PRONAF, possuem incentivos específicos para uma boa utilização e conservação do meio ambiente como, por

\footnotetext{
${ }^{4}$ Para que uma produção agrícola ou pecuária exercida em uma propriedade rural no país seja considerada de característica familiar, é preciso que haja integrantes da família que trabalhem no campo. No entanto, ainda não existe um conceito que esteja pontualmente definido sobre agricultura familiar, sendo que pelo senso comum, o agricultor familiar faz parte de várias maneiras de se praticar agricultura, considerando que existem as diferenças de culturas praticadas de cada família (SCHENEIDER; NIEDERLE, 2008).
} 
exemplo, o PRONAF Agroecologia e o PRONAF Eco, em que visam estimular a produção de produtos agroecológicos e orgânicos, além de investimentos em recuperação de uso de tecnologias de energia renovável e tecnologias ambientais (BNDES, 2015).

Também existe o Programa de Educação Ambiental e Agricultura Familiar (PEAAF), na qual é um programa de educação ambiental específico para a agricultura familiar, que tem como objetivo à adoção de práticas sustentáveis no território rural, mediante a esse setor específico. Além disso, visa promover a formação e capacitação da educação desses agricultores, assim resultando em um processo de incentivo para a educação ambiental dentro da agricultura familiar de modo geral (MMA, 2015).

Nesse contexto, o PEAAF incentivou o seminário ocorrido no ano de 2012: "Boas Práticas em Educação Ambiental na Agricultura Familiar", tratando sobre as temáticas da produção sustentável neste setor (ICMBIO, 2015). Considerando desta maneira a importância dessas duas temáticas para o desenvolvimento sustentável, quanto à produção de alimentos.

Além dos programas de incentivo na etapa produtiva e de educação ambiental, citados anteriormente, existe o Programa de Agricultura de Baixo Carbono, conhecido também como programa $A B C$, na qual é dividido em outros sete subprogramas (MAPA, 2015). O governo federal criou esse programa com o objetivo de incentivar toda a cadeia do agronegócio com relação às praticas ambientais, fazendo com que os produtores utilizem técnicas de agricultura sustentável para diminuir a quantidade de emissões de gases do efeito estufa.

Para que esse programa tenha efetividade, existem cursos para a capacitação dos agricultores, fazendo com que apliquem as técnicas corretas no processo de plantio. Seguindo essa linha de pensamento, o fato de existir um grande volume de produção e um grande volume de produtos gerados por parte dos produtores familiares no país, é preciso que haja uma produção que seja ecologicamente viável e sustentável para o meio ambiente em que está inserido. Desse modo, os aspectos analisados sobre educação ambiental, o qual foi citado anteriormente são de grande importância para a promoção da sustentabilidade ambiental. 
Contudo, além dos incentivos gerados pelos programas governamentais, existe a Lei № 12.651, de 25 de maio de 2012, que trata do código florestal, estabelecendo as obrigações para os produtores rurais variando de acordo com as características do imóvel rural e também dos tipos de atividades realizadas na propriedade. Nesta lei é indicado também para que os produtores façam sua inscrição no Cadastro Ambiental Rural (CAR), sistema em que permitirá um melhor controle da utilização da propriedade pelo governo, principalmente em questões que abordam áreas de preservação permanente e de reserva legal. Sendo assim, o cumprimento da lei faz com que em grande parte das áreas rurais ocorra uma produção de maneira mais eficiente, a fim de pensar a propriedade rural sob uma ótica sustentável.

\section{OBJETIVOS}

O presente trabalho possui como objetivo geral analisar os agricultores familiares da região de Tupã-SP, quanto as suas práticas e conhecimentos sobre educação ambiental aplicados em suas propriedades, podendo elas fazer parte do complexo agrícola ou pecuário.

Dentre os objetivos específicos estão: realizar um levantamento bibliográfico sobre educação ambiental e agricultura familiar; analisar a relação que existe entre os agricultores familiares com a educação ambiental diante as suas práticas de cultivo durante a produção e identificar dentre os produtores familiares entrevistados, quais são as culturas predominantes que existem em sua propriedade rural.

\section{METODOLOGIA}

A pesquisa foi desenvolvida sob uma abordagem metodológica qualitativa, que busca analisar e interpretar aspectos profundos e também descrever a complexidade do comportamento humano. Desse modo, fazendo com haja riquezas de detalhes das investigações, hábitos, ações, tendências comportamentais e entre outros aspectos peculiares (MARCONI; LAKATOS, 2011).

Dentro dessa abordagem, trata-se de uma pesquisa de caráter exploratório e descritivo que prioriza desenvolver e esclarecer conceitos e ideias, na qual visa à 
formulação de problemas mais precisos, sendo que envolve levantamento bibliográfico (GIL, 2014).

Contudo, além do levantamento bibliográfico e pesquisas em instituições especializadas, foi realizada uma pesquisa de campo para coleta de dados no município de Tupã, localizado no interior do estado de São Paulo. Para tanto, foi aplicado um formulário com 18 questões em que os sujeitos foram escolhidos de modo aleatório. Entretanto, para a aplicação das questões, buscou selecionar produtores que possuíam culturas diferentes em suas propriedades, com o objetivo de não obter distorções nas respostas, totalizando 12 agricultores familiares participantes dessa pesquisa.

O formulário composto por três blocos levou em consideração que cada bloco possui características próprias para serem analisadas. O Bloco A, teve por objetivo identificar as informações básicas dos agricultores, como sexo, idade e grau de escolaridade. É importante destacar que não foram identificados os nomes dos sujeitos nos formulários, tendo em vista que para a análise dos resultados não possui nenhum tipo de interferência. O Bloco B, por sua vez, buscou coletar dados para analisar os tipos de cultivos existentes na propriedade. A última etapa deste formulário composta pelo Bloco $\mathrm{C}$ visou identificar as práticas e percepções dos agricultores familiares sobre educação ambiental, adotando a escala Likert de cinco pontos como parâmetro de respostas, sendo a sequência de 1 a 5: “(1) Discordo Totalmente, (2) Discordo, (3) Indeciso, (4) Concordo e (5) Concordo Plenamente".

\section{RESULTADOS}

Por meio da coleta de dados pela pesquisa de campo, percebe-se que a partir das questões levantadas no Bloco A, ocorre uma predominância de $82 \%$ do sexo masculino, tendo a função de gestor nas propriedades analisadas, visto que apenas aproximadamente $8 \%$ dos produtores eram do sexo feminino. Além disso, somente $16 \%$ possuíam escolaridade de nível superior, demonstrando que ainda não é usual a continuidade dos estudos por meio do ensino superior, reforçando a importância do saber do campo, da prática vivenciada e repassada por gerações.

Juntamente com esses dados foi analisada a idade dos agricultores dividindo em seis faixas etárias. Nesta análise, percebeu-se que metade tinha até 50 
anos e que os outros 50\% possuíam acima de 51 anos, sendo que, deste modo, foi percebido que metade daqueles que possuíam acima desta idade, tinham apenas o ensino fundamental e, somente um entrevistado possuía o ensino superior.

As amostras foram coletadas de maneira aleatória como já citado anteriormente, no entanto procurou-se aplicar o formulário para produtores que tivessem culturas diferentes, etapa esta que foi analisada no Bloco B, com o intuito de realizar uma análise em que o tipo de cultivo produzido não tivesse interferência nos resultados. Dessa maneira, foram analisados agricultores dos mais diversos tipos de culturas, estando entre elas: amendoim, gado de leite, gado de corte, goiaba, limão, mandioca, milho, tomate, entre outras. Contudo, é importante destacar que entre as culturas predominantes não houve nenhuma que se repetiu e também que a produção de goiaba e mandioca esteve presente em grande parte das propriedades.

O Bloco C, por sua vez, foi utilizado para identificar o objetivo do presente trabalho, na qual foram realizadas 13 questões, levando em consideração que em 11 questões aplicou-se a metodologia proposta empregando a escala de Likert para análise dos resultados. A partir disso, foi identificado que $75 \%$ dos produtores entrevistados participam ou já participaram de algum tipo de programa governamental ligado com a Agricultura Familiar, sendo que todos estes fazem ou já fizeram parte do PRONAF, principal programa federal ligado neste setor.

Também foi questionado sobre a inscrição no Cadastro Ambiental Rural (CAR), em que dois em cada três produtores já realizaram o cadastro, assim estes que já o efetuaram, comprovam estar regularizado quanto às obrigações impostas pelo código florestal (Brasil, 2012). Entretanto, quando questionado aos entrevistados em relação aos benefícios que o CAR poderia trazer a sua propriedade, 92\% responderam que discordam ou discordam totalmente, ou seja, não estando de acordo com a efetuação do cadastro.

Neste contexto, cerca de $2 / 3$ dos produtores realizaram o CAR, sendo que a grande maioria não concorda que o cadastro poderá trazer benefícios para a sua propriedade. Apesar disso, todos eles afirmaram que cercam totalmente ou parcialmente as áreas de preservação permanente e de reserva legal. Assim, cerca de $90 \%$ respondeu que faz uso das práticas e preservação do meio ambiente pelo 
fato coercitivo de multas geradas por não desrespeitar a lei. Porém, vale ressaltar que o CAR ainda é recente e está em um processo de implantação.

Outro dado interessante coletado na elaboração deste trabalho é o fato de que todos utilizam algum tipo de agrotóxico no processo de produção, sendo que apenas metade faz devolução das embalagens dos produtos utilizados. Segundo a maioria deles, a devolução não ocorre pelo fato de que não existem pontos de coletas acessíveis. Alguns agricultores relataram que quando existia o ponto de coleta na Cooperativa Agrícola Mista da Alta Paulista (CAMAP) era realizado o processo de devolução das embalagens, mas por não existir esse procedimento atualmente, acaba gerando uma distância longa e um custo alto para a devolução em outras cidades.

Em relação à utilização da água nas propriedades, nenhum dos produtores acredita que a água poderá acabar algum dia, entretanto, todos afirmaram segundo seus conhecimentos fazer uso responsável da mesma durante a etapa de produção. Desta maneira, foi levantado sobre o conhecimento de cada um a respeito do conceito de sustentabilidade, sendo que todos afirmaram ter conhecimento sobre o assunto. Contudo, essa afirmação foi feita sobre seus próprios conhecimentos, tendo em vista que a abordagem sobre o conhecimento real de cada um dos produtores teria que ser realizada em outro estudo.

Foi percebido que na região não existem incentivos para estimular os produtores a realizar suas produções levando em consideração os aspectos ambientais, sendo que dos entrevistados apenas um produtor disse ter participado de algum tipo de ação ligado com a educação ambiental. Contudo, aproximadamente $92 \%$ acreditam que a utilização das práticas ambientais nas etapas de produção, independentemente da cultura a ser cultivada, ocorre de maneira positiva podendo melhorar a qualidade de vida das pessoas no campo.

É importante ressaltar que a partir desses resultados, nota-se a importância do Programa de Educação Ambiental e Agricultura Familiar (PEAAF) para que possa viabilizar ações continuas e participativas no campo com sujeitos sociais atuantes no setor da agricultura familiar. 


\section{CONCLUSÃO}

Considerando as três etapas do formulário, foi possível realizar uma comparação entre os blocos analisando as interferências entre eles, sendo possível identificar as práticas e percepções dos agricultores. Os resultados obtidos demonstraram que quanto às práticas executadas, é em grande parte realizada por fazer parte da legislação e em relação às percepções dos agricultores sobre o assunto, foi percebido que a grande maioria dos produtores acredita que é necessário conservar o meio ambiente para haja uma melhor qualidade de vida.

Deste modo, é descrito o cenário da agricultura familiar na região de TupãSP, possuindo grande parte dos gestores sendo homens de idade avançada e de baixo ou médio nível de escolaridade. Sendo assim, seria interessante se houvesse uma inserção de pessoas com maior grau de conhecimento e também de idade menos avançada para que haja um novo ciclo de produção e, além disso, para que se aplique um maior nível de conhecimento, com o objetivo de obter maiores níveis de produtividade, já que a Agricultura Familiar abastece com sua produção de alimentos grande parte da população.

Com relação ás práticas exercidas pelos agricultores entrevistados, podemos entender que as práticas executadas pelos mesmos, ocorrem na maioria das vezes pelo fato de haver uma legislação, na qual impõe a proteção do meio ambiente. Contudo, existem alguns tipos de práticas que não são impostas por lei, mas não são executadas por falta de infraestrutura.

Como exemplo das práticas executadas impostas por lei, podemos citar o cadastramento no CAR, em que os agricultores informam as áreas de preservação permanente e reserva legal, sendo que o produtor que não o fizer, estará passível de punição. Assim sendo, é um sistema governamental em que tenta regular de maneira punitiva as ações praticadas pelos agricultores, entretanto o ideal seria que, além disso, levasse a um processo de conscientização e não de punição para os agricultores, na qual é um tema proposto por NEUMANN e LOCH (2002), na metodologia deste trabalho.

Para estimular a prática de educação ambiental para os agricultores familiares seria necessário um papel de maior incentivo do governo, em que seria preciso implantar um sistema em que leve de maneira mais efetiva os conceitos de 
educação ambiental. Além disso, também deveria fornecer uma estrutura mais adequada para que seja realizado este processo, como, por exemplo, a criação de pontos de coleta para que haja a devolução das embalagens de agrotóxicos utilizadas no campo.

Sendo assim, nota-se que a educação ambiental é elemento fundamental e norteador no processo de gestão ambiental no meio rural. Desse modo, em relação à percepção dos agricultores sobre o assunto, pode-se dizer que a maioria acredita que a utilização da educação ambiental pode trazer benefícios tanto para a produção quanto para a qualidade de vida das famílias que estão inseridas neste meio. Entretanto, é necessário que haja, como já citado anteriormente, um apoio governamental para que conscientize de forma mais efetiva os agricultores familiares.

\section{REFERÊNCIAS BIBLIOGRÁFICAS}

AZEVEDO, F. F.; PESSÔA, V. L. S. O Programa Nacional de Fortalecimento da Agricultura Familiar no Brasil: Uma analise sobre a distribuição regional e setorial dos recursos. Revista em Sociedade \& Natureza. Uberlândia: ano 23 n. 3, p. 483-493, set. dez. 2011. Disponível em $<$ http://www.scielo.br/scielo.php?pid=S1982-45132011000300009\&script=sci_arttext $>$. Acessado em: 04 mai. 2015.

BNDES - Banco Nacional de Desenvolvimento. Disponível em: <http://www.bndes.gov.br/apoio/pronaf.html> Acessado em: 15 mai 2015.

BORDENAVE, J.D. O que é comunicação rural. 3. ed. São Paulo: Brasiliense, 1983.

BRASIL, 1999. Política Nacional de Educação Ambiental. Lei № 9.795 de 27 de abril de 1999. Disponível em < http://www.planalto.gov.br/ccivil_03/leis/19795.htm >. Acesso em: 22 abr 2015.

BRASIL, 2012. Lei № 12.651 de 25 de maio de 2012 . Disponível em: <http://www.planalto.gov.br/ccivil_03/_ato2011-2014/2012/lei//12651.htm>. Acessado em: 10 mai 2015.

BRASIL. Ministério da Agricultura, Pecuária e Abastecimento. Disponível em: $<$ http://www.agricultura.gov.br/desenvolvimento-sustentavel/plano-abc>. Acessado cem: 12 mai 2015c.

BRASIL. Ministério do Desenvolvimento Agrário. Disponível em: <http://www.mda.gov.br/portal/sra/programas >. Acessado em: 10 mai $2015 a$.

BRASIL. Ministério da Educação. Parâmetros Curriculares Nacionais: meio ambiente/saúde. Secretaria da Educação Fundamental 3 ed. Brasília: A Secretaria, 2001. 128p.

BRASIL. Ministério do Meio Ambiente. Programa de Educação Ambiental e Agricultura Familiar. Disponível em: <http://www.mma.gov.br/educacao-ambiental/formacao-de-educadores/programa-deeduca\%C3\%A7\%C3\%A3o-ambiental-e-agricultura-familiar-peaaf>.Acessado em: 20 mai 2015b. 
CODAF - Competências Digitais para Agricultura Familiar - Disponível em: < http://codaf.tupa.unesp.br/informacoes/a-importancia-da-agricultura-familiar> Acesso em: 10 mar 2015.

GIL, A. C. Métodos e Técnicas de Pesquisa Social. 6. ed. São Paulo: Atlas, 2014.

GUILHOTO; J.J.M. et al. PIB da Agricultura Familiar: Brasil - Estados. Brasília: MDA, 2007.

ICMBIO - Instituto Chico Mendes de Conservação de Biodiversidade. Disponível em: $<$ http://www.icmbio.gov.br/educacaoambiental/destaques/51-seminario-de-boas-praticas-emeducacao-ambiental-na-agricultura-familiar.html>. Acessado em: 21 mai 2015.

KAGEYAMA, A. Desenvolvimento Rural: Conceitos e Aplicações ao Caso Brasileiro. Porto Alegre: UFRGS: Programa de Pós Graduação em Desenvolvimento Rural, 2008.

LEFF, E. Saber Ambiental: sustentabilidade, racionalidade, complexidade, poder; tradução ORTH, L.M.E. 5a․ ed. Petrópolis, RJ: Vozes, 2007.

MARCONI, M. de A.; LAKATOS, E. M. Metodologia Científica. 6. ed. São Paulo: Atlas, 2011.

MORALES, A. G. A formação do profissional educador ambiental: reflexões, possibilidades e construções. Ponta Grossa: Ed. UEPG, 2012.

NEUMANN, P. S.; LOCH, C. Legislação ambiental, desenvolvimento rural e práticas agrícolas. Revista Cienc. Rural. v.32, no2. Santa Maria, abr. 2002. Disponível em <http://www.scielo.br/scielo.php?pid=S0103-84782002000200010\&script=sci_arttext>. Acessado em: 20 abr 2015.

SAUVÊ, L. Educação ambiental: possibilidades e limitações. Educação e Pesquisa. São Paulo. v. 31 , n. 2, p. 317 - 322. mai/ago 2005. Disponível em < www.revistas.usp.br/ep/article/download/27979/29759 >. Acesso em abr. 2015.

SCHENEIDER, S.; NIEDERLE, P. A. Agricultura familiar e teoria social: a diversidade das formas familiares de produção na agricultura. In. Savanas: desafios e estratégias para o equilíbrio entre sociedade, agronegócio e recursos naturais. FALEIRO, F. G.; FARIAS NETO, A. L. de (Ed.). Capítulo 32, p. 989 - 1012. Planaltina DF: Embrapa Cerrados, 2008. Disponível em < www.embrapa.br/buscade-publicacoes/-/publicacao/570974/savanas-desafios-e-estrategias-para-o-equilibrio-entresociedade-agronegocio-e-recursos-naturais $\mathrm{f}>$. Acesso em abr. 2015.

VICTORINO, C. J. A. Canibais da Natureza: educação ambiental, limites e qualidades de vida. Petrópolis: Vozes, 2000. 